\title{
ANÁLISE BIVARIADA, MULTIVARIADA E ESPACIAL DA OCORRÊNCIA DO SARS-CoV-2 NOS MUNICÍPIOS DO ESTADO DO PIAUÍ, NORDESTE DO BRASIL
}

\section{BIVARIATED, MULTIVARIATE AND SPATIAL ANALYSIS OF SARS-CoV-2 OCURRENCE IN THE MUNICIPALITIES OF THE STATE OF PIAUÍ, NORTHEAST OF BRAZIL}

\author{
Francílio de Amorim dos Santos \\ Instituto Federal do Piauí, Campus Piripiri, PI, Brasil \\ francilio.amorim@ifpi.edu.br \\ Lúcia Maria Silveira Mendes \\ Universidade Estadual do Ceará, Campus Itaperi, CE, Brasil \\ lucia.mendes@uece.br
}

\begin{abstract}
RESUMO
O estudo teve como objetivo realizar classificação e análise de um grupo de variáveis independentes - gênero (masculino e feminino), população residente (\% da população com $\geq 65$ anos), saúde (número de estabelecimentos) - associadas à variável dependente número de casos confirmados, para definição da similaridade dos municípios piauienses em relação à ocorrência do SARS-CoV-2. O estudo constitui uma pesquisa descritiva quanto a seu objetivo e empregou técnicas estatísticas para manuseio das informações referentes às variáveis elencadas, obtidas via banco de dados do IBGE e SESAPI. Os dados apontaram que no período de 18 de março a 05 de junho haviam 7.105 casos confirmados e 224 óbitos causados por SARS-CoV-2 no Piauí. A análise estatística apontou que o coeficiente de determinação se mostrou ótimo, pois apresentou valores acima de 0,9 em todos os casos, cuja variável mais fortemente correlacionada aos casos confirmados de covid-19 foi a população do sexo feminino, com coeficiente de correlação de 0,9913. A análise de agrupamentos apontou que nos clusters 1 agrupam-se municípios de pequeno porte, menor contingente populacional e menor quantitativo de estabelecimentos de saúde, enquanto nos clusters 5 ficou apenas o município de Teresina, capital do estado, que apresenta maior contingente populacional e número de estabelecimentos de saúde total.
\end{abstract}

Palavras-chave: Covid-19. Municípios piauienses. Correlação. Análise de agrupamentos.

\begin{abstract}
The study aimed to classify and analyze a group of independent variables - gender (male and female), resident population ( $\%$ of the population $\geq 65$ years old), health (number of establishments) - associated with the dependent variable number of confirmed cases, to define the similarity of Piaui's municipalities in relation to the occurrence of SARS-CoV-2. The study constitutes a descriptive research as to its objective and used statistical techniques for handling the information related to the listed variables, obtained via the IBGE and SESAPI database. The data showed that in the period from March 18 to June 5, there were 7,105 confirmed cases and 224 deaths caused by SARS-CoV-2 in Piauí. The statistical analysis showed that the determination coefficient was excellent, as it presented values above 0.9 in all cases, whose variable most strongly correlated to confirmed cases of covid-19 was the female population, with a correlation coefficient. of 0.9913 . The analysis of clusters showed that in clusters 1 small municipalities are grouped, with a smaller population and a smaller number of health facilities, while in clusters 5 only the municipality of Teresina, the state capital, has the largest population and the largest number. of total health facilities.
\end{abstract}

Keywords: Covid-19. Piauí municipalities. Correlation. Cluster analysis.

Recebido em: 15/06/2020

Aceito para publicação em: 03/08/2020. 


\section{INTRODUÇÃO}

Muitas informações têm sido disseminadas nos últimos meses acerca da pandemia oriunda da SARSCoV-2 ou Covid-19 (Severe Acute Respiratory Syndrome Coronavirus 2), virose já considerada um desastre mundial de natureza biológica. Entretanto, muitas dessas informações nem sempre são bem fundamentadas, conforme afirmam Sposito e Guimarães (2020). Desse modo, torna-se essencial a aplicação de técnicas de geoprocessamento na organização de um banco de dados com dados confiáveis e, posteriormente, sua disponibilização à sociedade por meio e publicações em veículos com reconhecida confiabilidade e credibilidade.

Nesse sentido, o agrupamento de informações via banco de dados e a respectiva espacialização em Sistema de Informação Geográfica (SIG) pode subsidiar ações localizadas no combate à referida pandemia. É importante ressaltar que Shepherd (2020) indica esse tipo de trabalho de cunho geográfico, alicerçado em ferramentas e técnicas associado às tecnologias geográficas, tem sido cada vez mais importante para entender a complexidade de ocorrências mundiais diversas.

Belforte et al. (2020) destacam que a Geografia tem contribuído para a espacialização e análise da covid-19, particularmente devido à localização de casos suspeitos, confirmados e de óbitos, informações que permitem a adoção de estratégias para a redução do avanço da doença e o correto uso das informações resultantes do monitoramento. O referido estudo vem apontar a relevância da Geografia e também da Cartografia como uma possibilidade concreta para estudos epidemiológicos.

Nesse sentido, a pesquisa classifica-se como descritiva quanto ao seu objetivo e empregou estatística bivariada - Coeficiente de Determinação $\left(R^{2}\right)$, Coeficiente de Correlação de Pearson $(r)$ e Coeficiente de Regressão Linear - e estatística multivariada - método Análise de Agrupamentos (AA) -, como possibilidade para identificação da similaridade dos municípios piauienses no que diz respeito ao Covid19. De acordo com Rogerson (2012), a Análise de Agrupamentos busca agrupar observações semelhantes e, de acordo com Mingoti (2005), estabelecer a divisão dos elementos da amostra em grupos, onde os elementos pertencentes a um mesmo grupo sejam similares entre si no que diz respeito às variáveis neles mensuradas.

É importante ressaltar o estudo de Almagro e Orane-Hutchinson (2020) que utilizou diferentes modelos de regressão para explicar as disparidades na incidência de Covid-19 nos bairros de Nova York. Também estudando o comportamento da doença, Barbieri, Basso e Scicchitano (2020) empregaram o Índice de Proximidade Física para analisar, nas ocupações italianas que operam em cerca de 600 setores, o risco de contágio da virose durante a pandemia e a correlação entre exposição a doenças infecciosas e proximidade física dos trabalhadores. Desse modo, os estudos reiteram a importância do uso de índices e/ou técnicas estatísticas nos estudos relacionados à compreensão do Covid-19.

O estudo teve como objetivo realizar a classificação e análise de um grupo de variáveis independentes - gênero (masculino e feminino), população residente (\% da população com idade $\geq 65$ anos), saúde (número de estabelecimentos) - associadas à variável dependente número de casos confirmados, para definição da similaridade dos municípios piauienses em relação à ocorrência do Covid-19. Diante do exposto, evidencia-se a relevância da pesquisa como um importante recurso para agrupamento de variáveis e disponibilização das mesmas à sociedade piauiense, permitindo à população obter informações estratégicas seguras, de forma rápida e sem custo. Destaque-se ainda que foi possível categorizar os municípios piauienses por níveis de similaridade a partir de procedimentos estatísticos, possibilitando a identificação das relações entre as variáveis estudadas e o número de óbitos causados por Covi-19.

\section{MATERIAIS E MÉTODOS}

\section{$A$ área em estudo}

O estado do Piauí está localizado na região Nordeste do Brasil e apresenta os seguintes limites: ao norte o oceano Atlântico, a leste os estados do Ceará e de Pernambuco, ao sul os estados da Bahia e do Tocantins, a oeste o estado do Maranhão (Figura 1). Baptista (1981) ressalta que o Piauí exibe os seguintes pontos extremos: a norte a barra das Canárias (02 $44^{\prime} 07^{\prime \prime S}$ e $\left.41^{\circ} 48^{\prime} 49^{\prime \prime} \mathrm{O}\right)$, ao sul as cabeceiras do rio Paraim ( $10^{\circ} 53^{\prime} 05^{\prime \prime} \mathrm{S}$ e $\left.45^{\circ} 04^{\prime} 31^{\prime \prime} \mathrm{O}\right)$; a leste as nascentes do rio Canindé $\left(06^{\circ} 49^{\prime} 03^{\prime \prime S}\right.$ e $40^{\circ} 29^{\prime} 00^{\prime \prime O}$ ) e a oeste a foz do rio Parnaíba ( $08^{\circ} 54^{\prime} 09^{\prime \prime S}$ e $\left.46^{\circ} 00^{\prime} 24^{\prime \prime} \mathrm{O}\right)$. O estado em questão possui uma área de 251.611,929 km², com uma população estimada, em 2019, de 3.273 .227 habitantes, densidade demográfica de 13,01 hab./km² e, atualmente, conta com 224 municípios (IBGE, 2020c).

\begin{tabular}{llllll}
\hline DOI:http://dx.doi.org/10.14393/Hygeia16055472 & Hygeia & v.16 & p. 249-263, 2020 & página 250
\end{tabular}


O estado do Piauí apresenta uma forma irregular, possuindo de norte a sul $901 \mathrm{~km}$ de extensão e de leste a oeste $609 \mathrm{~km}$ (BAPTISTA, 1981). Geologicamente está assentado sobre o embasamento cristalino Pré-Cambriano, sedimentos paleozoicos da Bacia Sedimentar do Maranhão-Piauí, sedimentos terciários da Formação Barreiras e sedimentos costeiros quaternários, ao passo que suas maiores altitudes estão ligadas à Chapada das Mangabeiras, que está $880 \mathrm{~m}$ acima do nível do mar (LIMA, ABREU, LIMA, 2000).

O estado, de acordo com Lima, Abreu e Lima (2000), possui duas sub-regiões, a saber: uma semiárida, com uma probabilidade superior a $75 \%$ de que o índice de chuva anual seja inferior a $900 \mathrm{~mm}$ e 2 a 3 meses favoráveis à ocorrência de chuvas, com vegetação predominantemente do tipo caatinga, com estratos arbóreos e/ou arbustivos; e uma transição semiárida, com probabilidade superior a $75 \%$ de que o índice de chuva anual seja abaixo de $900 \mathrm{~mm}$ e com 4 ou mais meses favoráveis à ocorrência de chuvas, com presença de caatingas associadas ora ao cerrado ora à mata de palmáceas, com manchas de degradação da cobertura vegetal.

Figura 1 - Localização do estado do Piauí, região Nordeste do Brasil.

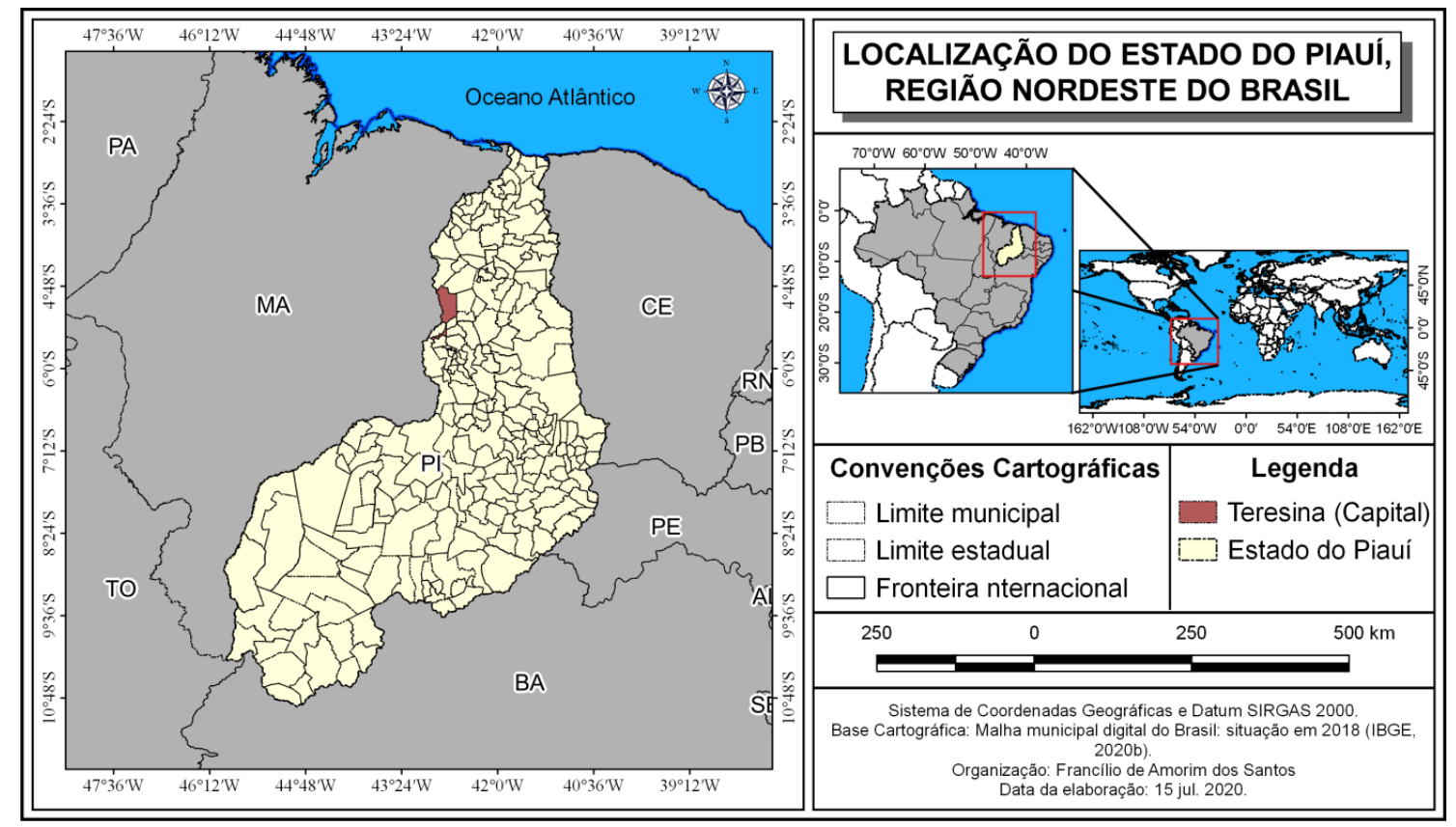

Fonte: IBGE (2020b); SESAPI (2020). Organizado por Santos (2020).

\section{Procedimentos metodológicos}

A pesquisa constitui-se num estudo descritivo quanto ao seu objetivo, posto que se tenha buscou relacionar algumas variáveis consideradas independentes e o número de casos confirmados de infecção por Covid-19 no estado do Piauí. Empregou-se, também, abordagem quantitativa, tendo em vista que foram empregadas técnicas estatísticas para o manuseio das informações obtidas, particularmente devido ao uso da estatística bivariada - Coeficiente de Determinação $\left(R^{2}\right)$ e Coeficiente de Correlação de Pearson ( $r$ - - e estatística multivariada (análise de agrupamentos).

$\mathrm{O} \mathrm{R}^{2}$ diz respeito a uma medida de ajuste que avalia a adequabilidade do modelo estatístico linear generalizado, ou seja, avalia quanto o modelo é capaz de explicar os dados coletados, esse ajuste varia de 0 a 1 e quanto mais próximo a 1 mais adequado é o modelo (PORTAL ACTION, 2020).

O r diz respeito ao grau de associação entre duas variáveis, ao passo que na correlação de Pearson indica-se o nível de associação linear entre variáveis com dados na escala de intervalo, podendo variar 
de -1 , quando o aumento de uma variável resulta na diminuição da outra, $a+1$, quando o valor de uma variável resulta no aumenta da outra (GERALDI; SILVA, 1981).

A pesquisa considerou ainda a realização de levantamento bibliográfico e de dados vetoriais e alfanuméricos, esses obtidos a partir do banco de dados do Instituto Brasileiro de Geografia e Estatística (IBGE, 2020a; 2000b) e Secretaria de Estado da Saúde do Piauí (SESAPI, 2020). Desse modo, foram adquiridos dados do IBGE para as seguintes variáveis: gênero feminino (Vindep01); gênero masculino (Vindep02); \% população residente com 65 anos de idade ou mais (Vindep03); número de estabelecimentos de saúde (Vindep04) - postos e centros de saúde, clínicas, prontossocorros, unidades mistas, hospitais, laboratórios e unidades de complementação diagnóstica e/ou terapêutica; da SESAPI (2020) foram obtidos dados referentes ao número de casos confirmados de Covid-19 (Vdep01) e número de óbitos por Covid-19 (Vdep02), apresentados por local de residência do paciente, considerando-se o dia de 05 de junho de 2020.

De posse dos dados para essas variáveis, foi possível utilizar a análise de agrupamentos, como possibilidade para agrupar observações semelhantes no que diz respeito às variáveis mencionadas. Foi utilizado o método aglomerativo, onde se vão fundindo dois grupos, resultando em $n-1$ grupos, até que permaneça apenas um único grupo, que contém todas a $n$ observações, ressaltando-se que a união de dois grupos em cada etapa da análise não pode ser desfeita nos estágios posteriores (ROGERSON, 2012).

Mingoti (2005) destaca que em cada etapa do referido método os elementos amostrais vão sendo agrupados em um cluster de tamanho 1, cuja propriedade hierárquica está ligada à fusão inseparável nos estágios posteriores, nesse estudo o número de clusters delimitados foram 5 . Ao passo que a similaridade diz respeito ao fato de que quanto maior o valor observado, mais semelhante são as observações, considerando-se a distância euclidiana.

Os procedimentos efetuados para aquisição dos valores referentes ao $\mathrm{R}^{2}$ e ao $\mathrm{r}$ foram executados no software BioEstat, versão 5.0, enquanto que para efetivação dos procedimentos inerentes à análise de agrupamentos utilizou-se o software SPSS Statistics, com cinco clusters como número de grupos a serem produzidos, utilizando-se o método do vizinho mais próximo e funções ligadas à ferramenta Analyze do referido software. Foi utilizado também o Sistema de Informação Geográfica (SIG) QGIS, versão 2.14, para espacialização dos dados das variáveis, supracitadas, considerando-se a opção graduado e método quebra natural (jenks).

\section{RESULTADOS E DISCUSSÃO DOS DADOS}

Na Figura 2 observam-se informações relacionadas ao número de casos confirmados e isolamento social por Covid-19 e percentual de isolamento social, onde se pode observar que a curva relacionada aos casos confirmados continua em ascensão, não tendo desacelerado mesmo quando o nível de isolamento social ultrapassou os $50 \%$. Tal fato ocorreu em apenas 15 dos 80 dias analisados (18 de março a 5 de junho), destacando-se o dia 22 de março, tendo sido o dia em que o estado do Piauí atingiu $58,9 \%$ de isolamento social, com apenas 6 casos confirmados de Covid-19. O número de casos de óbitos confirmados acumulados no estado do Piaú teve curva acentuada principalmente a partir do mês de maio, atingindo 26 óbitos no dia $1^{\circ}$, provavelmente ligado ao aumento do número de casos confirmados de infecção por Covid19 , fruto principalmente da redução dos níveis de isolamento que, com exceção do dia 31 de maio $(51,8 \%)$, sempre estiveram abaixo de $50 \%$ nesse mês.

É relevante afirmar que embora o percentual de isolamento social não tenha apresentado correlação com os casos confirmados acumulados e óbitos acumulados por conta da Covid-19, não se pode abrir mão dessa medida de contenção. É preciso atentar-se para o fato de que a redução da taxa de isolamento social e a tendência ao aumento do número de casos confirmados de pessoas com covid-19 devem ser relacionados ao percentual de leitos disponíveis no estado para atendimento às pessoas acometidas com a doença, sob pena de colapso do sistema público e privado de saúde. 
Análise bivariada, multivariada e espacial da ocorrência do SARS-CoV-2 nos municípios do estado do Piauí, nordeste do Brasil
Francílio de Amorim dos Santos Lúcia Maria Silveira Mendes

Figura 2 - Número de casos confirmados acumulados e óbitos acumulados por Covid-19 e percentual de isolamento social, no período de 18 de março a 05 de junho de 2020.

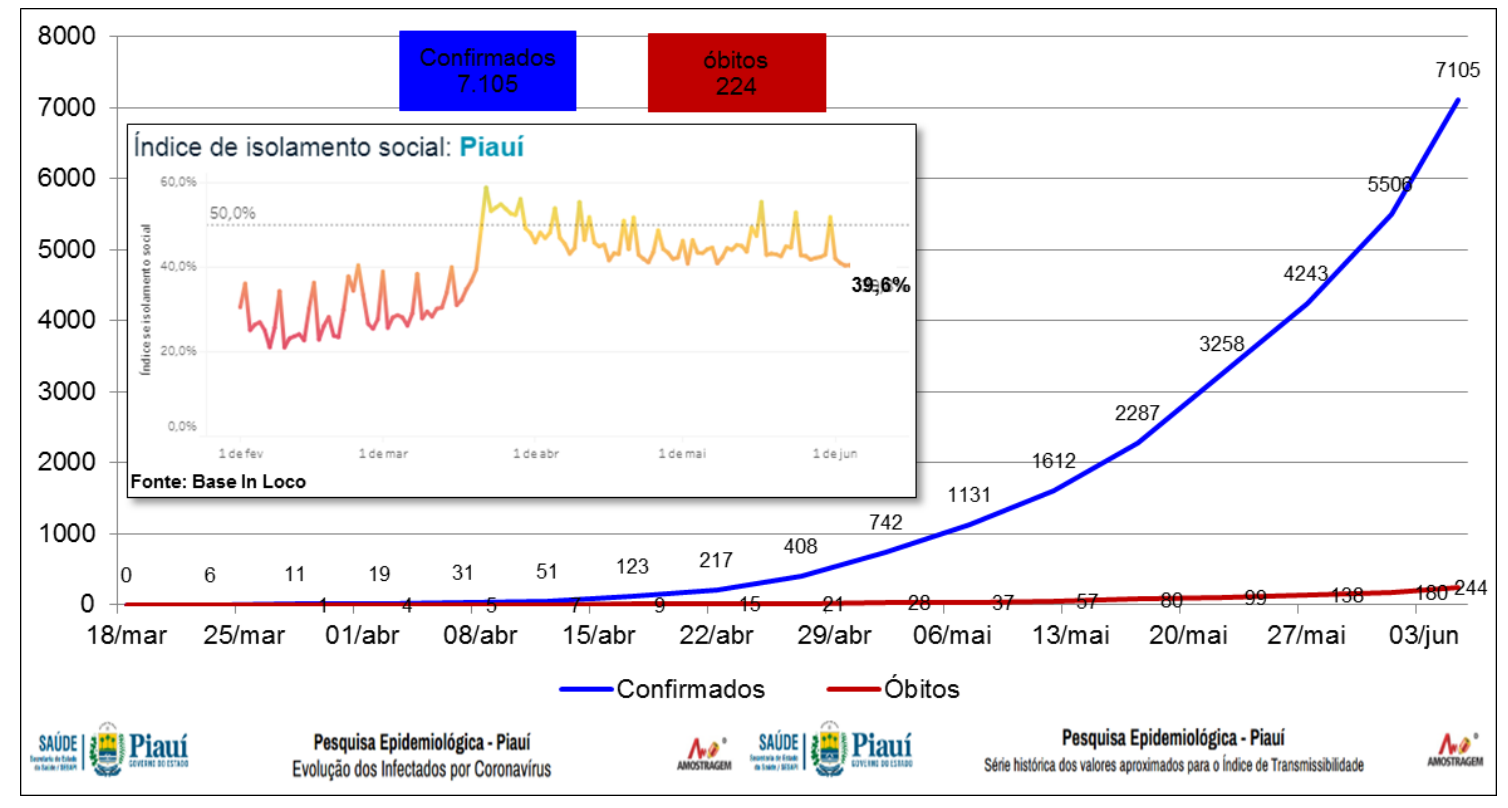

Fonte: In Loco (2020); SESAPI (2020). Adaptado por Santos (2020).

Figura 3 - Incidência dos casos de Covid-19/1000 habitantes nos municípios do estado do Piauí, em 05.06.2020.

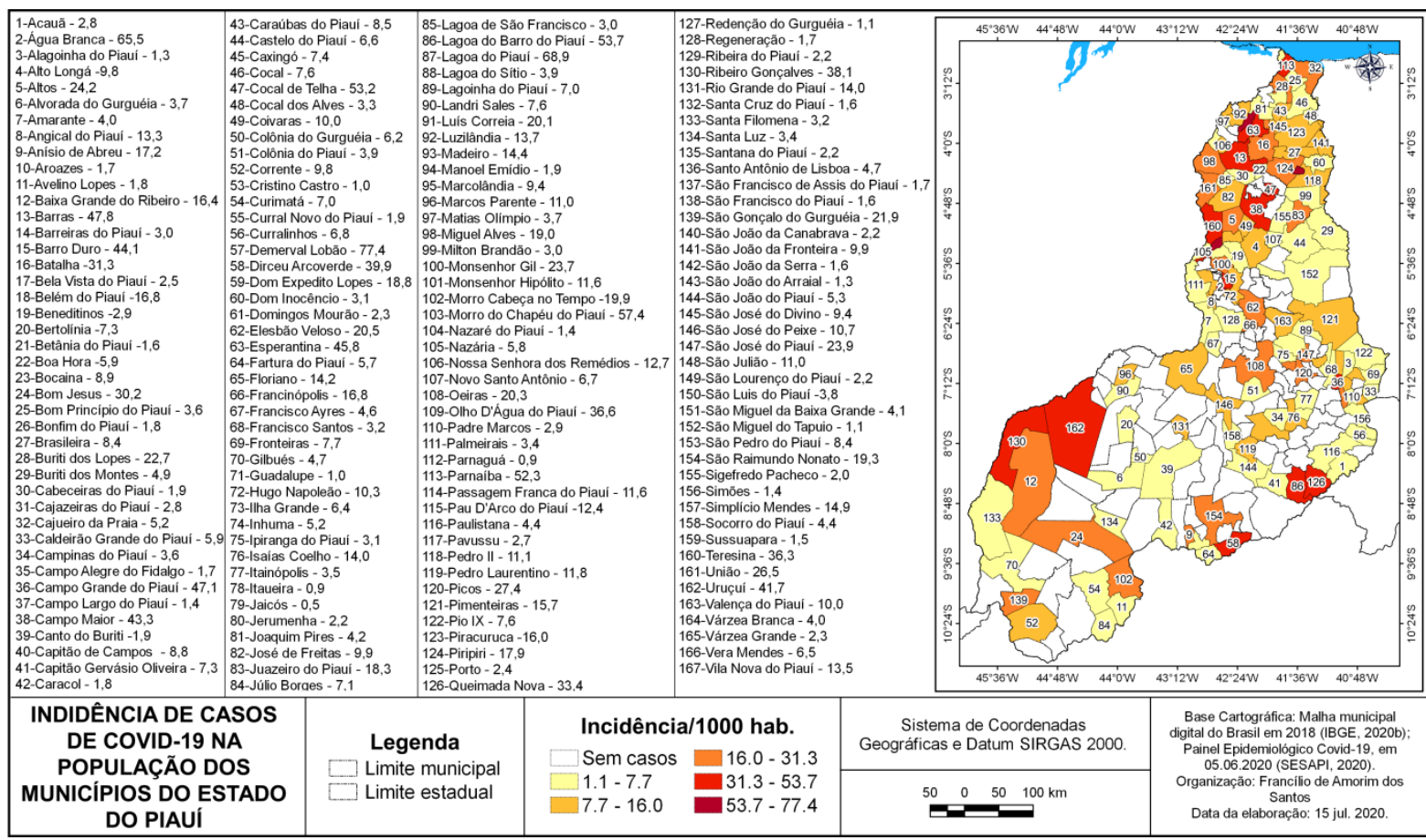

Fonte: IBGE (2020b); SESAPI (2020). Organizado por Santos (2020). 
No que diz respeito à incidência (Figura 3), o quantitativo de casos na população piauiense, para o dia 05 de junho de 2020, apontou predomínio da classe 1.1 a 7.7, que agrega 93 municípios, particularmente aqueles localizados no centro-sul do referido estado, seguido pela classe. Ao passo 7.7 a 16.0, que compreendem 33 municípios piauienses, concentrando-se principalmente no norte do estado, tendo como destaque o munícipio de Piracuruca - incidência de 16 casos - considerado epicentro dessa área. Por sua vez, as classes 16.0 a 31.3, 31.3 a 53.7 e 53.7 a 77.4 abrangeram, respectivamente, 22 (norte do estado), 14 (centro-norte e sul do estado) e 5 municípios (centro do estado). A última classe (53.7 a 77.4) destaca-se por apresentar 5 municípios (Lagoa do Barro do Piauí, Morro do Chapéu do Piauí, Água Branca, Lagoa do Piauí e Demerval Lobão) com quantitativo populacional abaixo de 20 mil habitantes, apontando alto índice de contágio entre a população desses municípios.

$\mathrm{Na}$ Figura 4 são apresentados os percentuais de leitos clínicos, de UTI, de estabilização e com respiradores para o estado do Piauí, onde se pode perceber que no estado, em 05 de junho, estavam à disposição: $65,8 \%$ de leitos clínicos, $38,5 \%$ leito UTI, $81,8 \%$ leitos de estabilização e $44,7 \%$ de leitos com respirador. Destaca-se, desse modo, que os leitos UTI encaminham-se para um nível que põem em risco a oferta do serviço público de saúde, fato que poderá resultar em colapso e acentuação dos casos de óbito no estado.

Figura 4 - Percentual de leitos clínicos, leitos de UTI, leitos de estabilização e leitos com respiradores disponíveis e ocupados no estado do Piauí, em 09.06.2020.

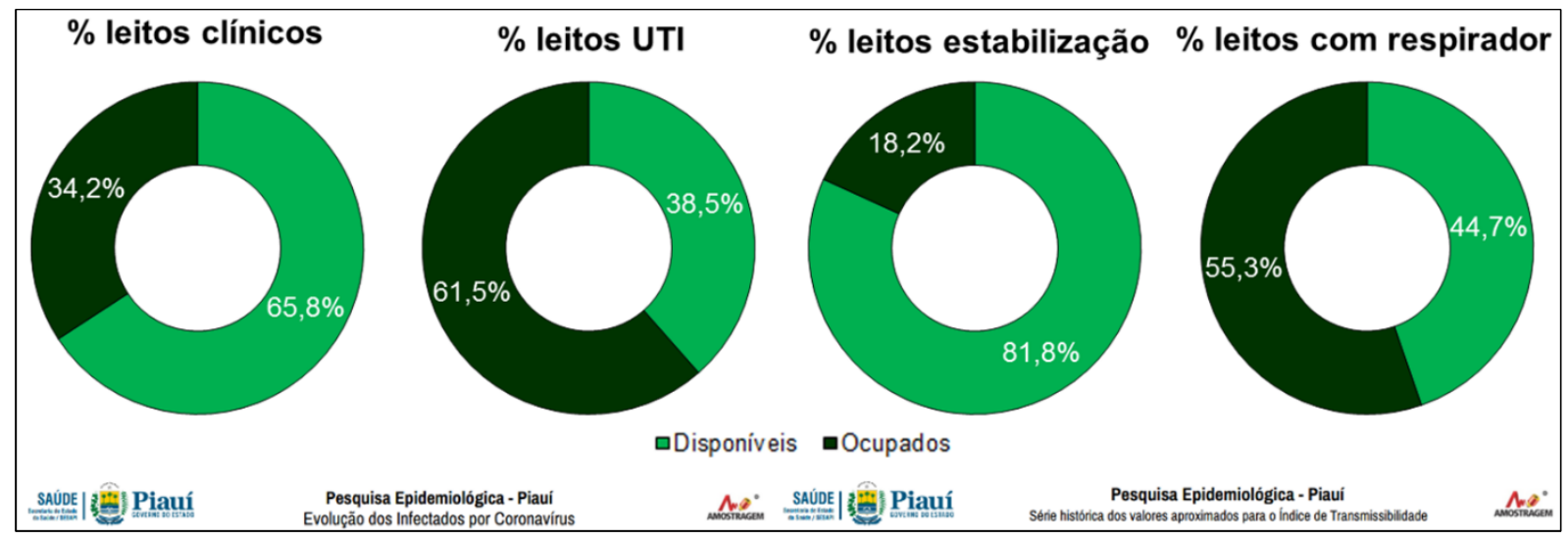

Fonte: SESAPI (2020). Organizado por Santos (2020).

\section{Análise da estatística bivariada}

O modelo de correlação empregado entre a variável população do sexo feminino e casos confirmados de Covid-19 foi adequado, posto que o coeficiente $\mathrm{R}^{2}$ apresentou valor de 0,9827 , considerado ótimo. Por sua vez, o coeficiente de correlação apontou forte ligação entre a infecção por Covid-19 e o sexo feminino, como mostra a Figura 5, tendo o coeficiente $r$ atingido 0,9913, permitindo ratificar os dados da SESAPI (2020), que apontaram que até 5 de junho 3.691 mulheres haviam sido infectadas contra 3.414 homens. Desse modo, os municípios de Piripiri (30.138), Picos (35.061), Parnaíba (69.727) e Teresina (380.612) são aqueles com maior quantidade de pessoas do sexo feminino (IBGE, 2020a). Ressalta-se, ainda, que a população do sexo feminino tem sido a mais afetada que a masculina em termos de infecção por Covid-19, de acordo com dados da SESAPI (2020). Quando se observam os mapas, percebe-se o alinhamento dos casos confirmados de infecção por Covidd-19 e a população do sexo feminino, principalmente nas últimas classes delimitadas, com destaque para a capital, Teresina. 
Figura 5 - Correlação entre a população do sexo feminino e os casos confirmados de covid-19 (em 05.06.2020), para os municípios do estado do Piauí.

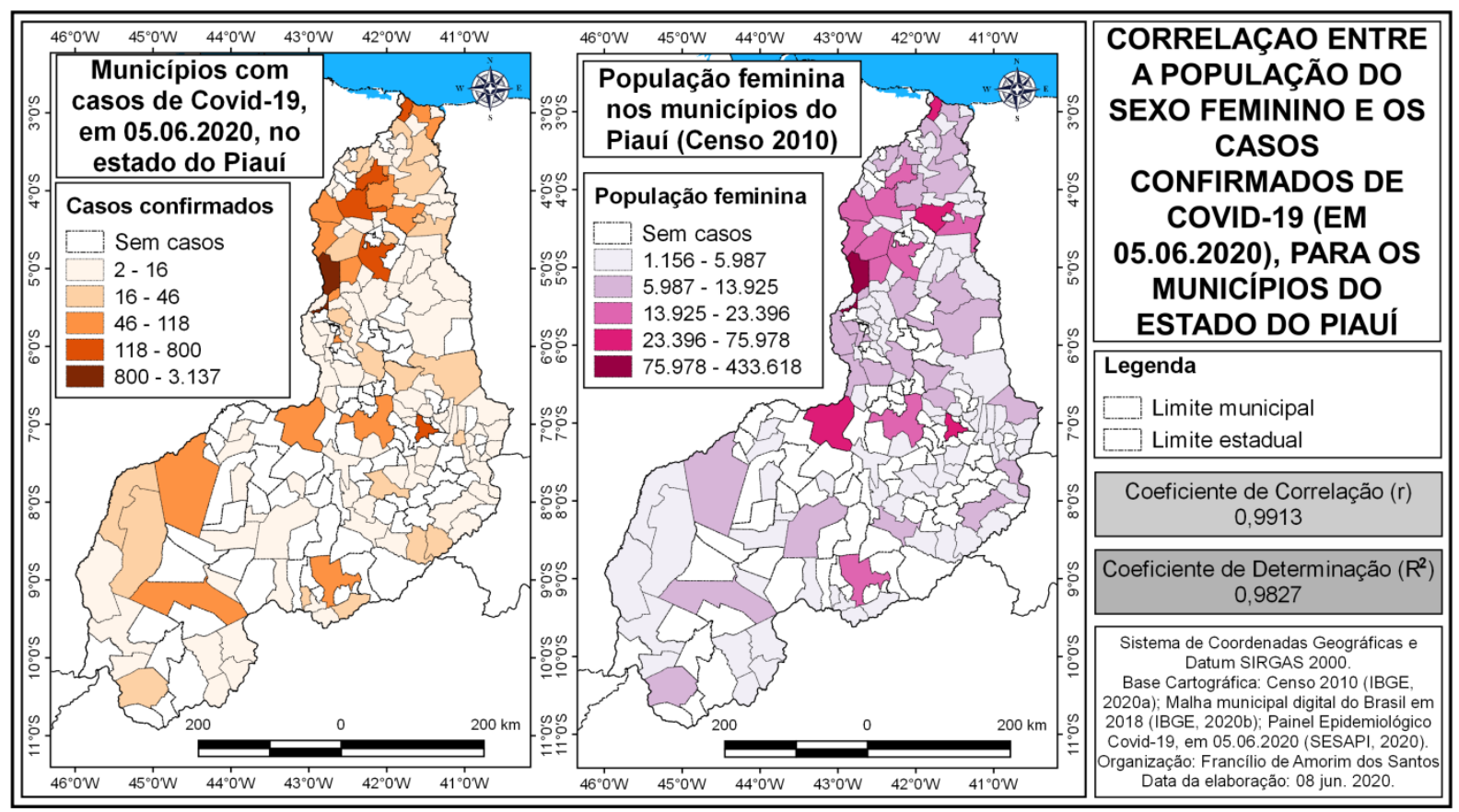

Fonte: IBGE (2020a; 2020b); SESAPI (2020). Organizado por Santos (2020).

A Figura 6 apresenta os mapas de correlação entre a variável população do sexo masculino e os municípios piauienses com casos confirmados de Covid-19. Aqui destaca-se que o coeficiente de determinação demonstrou que o modelo utilizado foi adequado, pois o $R^{2}$ foi de 0,9820 , considerado ótimo. $O$ coeficiente de correlação exibiu forte ligação entre a infecção por Covid-19 e o sexo masculino. Contudo, em relação ao sexo feminino, o número de homens infectados até 5 de junho foi de 3.414 contra 3.691 mil mulheres infectadas (SESAPI, 2020), mostrando que a doença tem acometido mais o gênero feminino. Destaca-se que os municípios de Floriano (30.381), Piripiri (31.696), Picos (38.353), Parnaíba (75.978) e Teresina (433.618) são aqueles com o maior número de pessoas do sexo masculino (IBGE, 2020a). Cabe salientar que os dados da SESAPI (2020) apontam para o fato de que, embora a população feminina seja mais atingida, a população masculina tem apresentado maior número de óbitos.

A Figura 7 exibe a correlação entre a variável população com 65 anos ou mais de idade e os casos confirmados de Covid-19, a qual evidenciou um coeficiente $R^{2}$ no valor de 0,9735 , modelo considerado adequado. Pode-se perceber que entre as variáveis com relação alta e positiva o coeficiente $r$ foi de 0,9867 . Cabe salientar que a Organização Mundial de Saúde (OMS, 2020), preconiza que indivíduos acima de 60 anos encontram-se no grupo de risco, particularmente devido às alterações naturais que ocorrem no sistema imunológico com a idade, favorecendo a agressividade da infecção. Nesse sentido, ao se observar os mapas, vê-se um alinhamento entre os municípios com maior quantidade de idosos e o maior número de casos confirmados de infecção por Covid-19, onde se destacam os municípios de Teresina, capital do estado, e Parnaíba, respectivamente com 46.113 e 11.072 pessoas com 65 anos ou mais de idade. 
Análise bivariada, multivariada e espacial da ocorrência do SARS-CoV-2 nos municípios do estado do Piauí, nordeste do Brasil
Francílio de Amorim dos Santos Lúcia Maria Silveira Mendes

Figura 6 - Correlação entre a população do sexo masculino e os casos confirmados de covid-19 (em 05.06.2020), para os municípios do estado do Piauí.

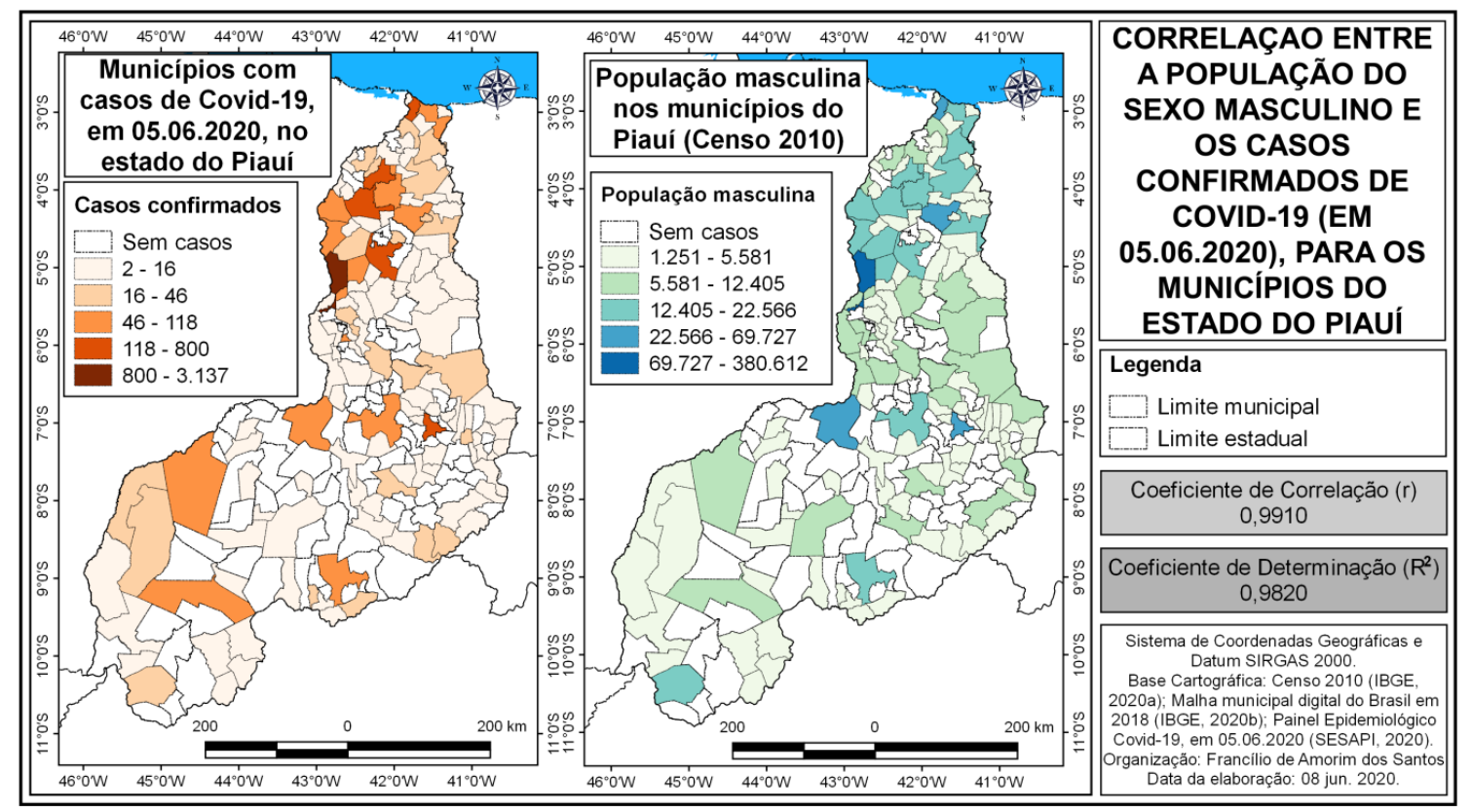

Fonte: IBGE (2020a; 2020b); SESAPI (2020). Organizado por Santos (2020).

Figura 7 - Correlação entre a população com 65 anos de idade ou mais e os casos confirmados de covid-19 (em 05.06.2020), para os municípios do estado do Piauí.

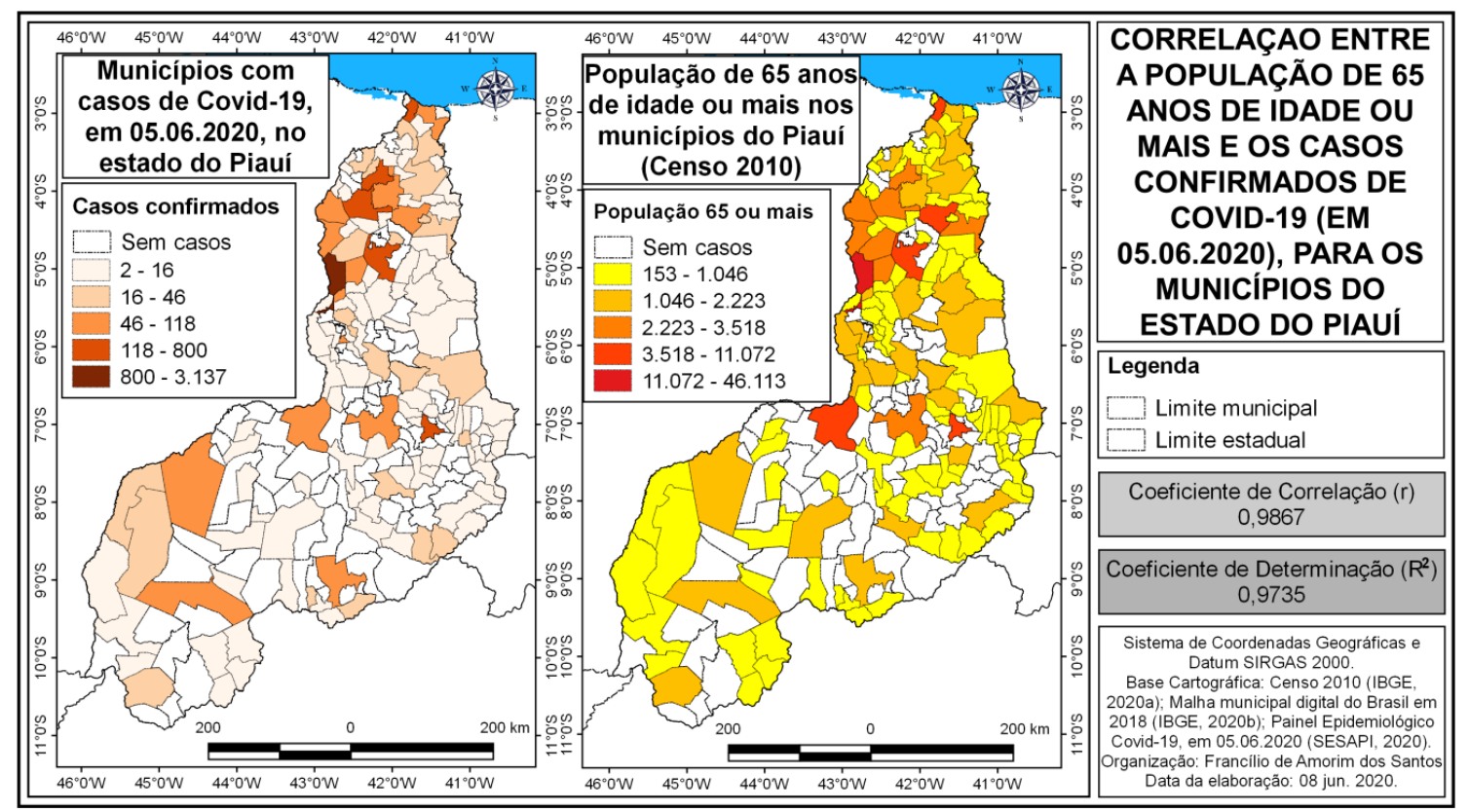

Fonte: IBGE (2020a; 2020b); SESAPI (2020). Organizado por Santos (2020).

Na Figura 8 pode ser observada a correlação realizada entre a variável número de estabelecimento de saúde e os casos confirmados de covid- 19 , cujo valor de $R^{2}$ de 0,9027 , considerado adequado. Ressaltase que ocorre entre as variáveis uma correlação alta e positiva, com o coeficiente $r$ foi de 0,9501 . Dessa maneira, os municípios de Floriano (66), Parnaíba (85), Picos (114) e Teresina (366) sobressaem-se 
como aqueles com maior quantidade de estabelecimentos de saúde total, considerados os municípios piauienses com o maior contingente populacional e, como tal, demandando maior quantitativo de estabelecimentos de saúde para atendimento à população. Cabe dizer que esses municípios considerados de médio a grande porte funcionam como polo de atração populacional, particularmente quando considerados os estabelecimentos de saúde com potencial para atendimento a pessoas com caso confirmado por Covid-19, de tal modo que se deve atentar para sua capacidade de saturação em relação a esse atendimento, sob pena de colapso no sistema de saúde.

Figura 8 - Correlação entre o número de estabelecimentos de saúde total e os casos confirmados de covid-19 (em 05.06.2020), para os municípios do estado do Piauí.

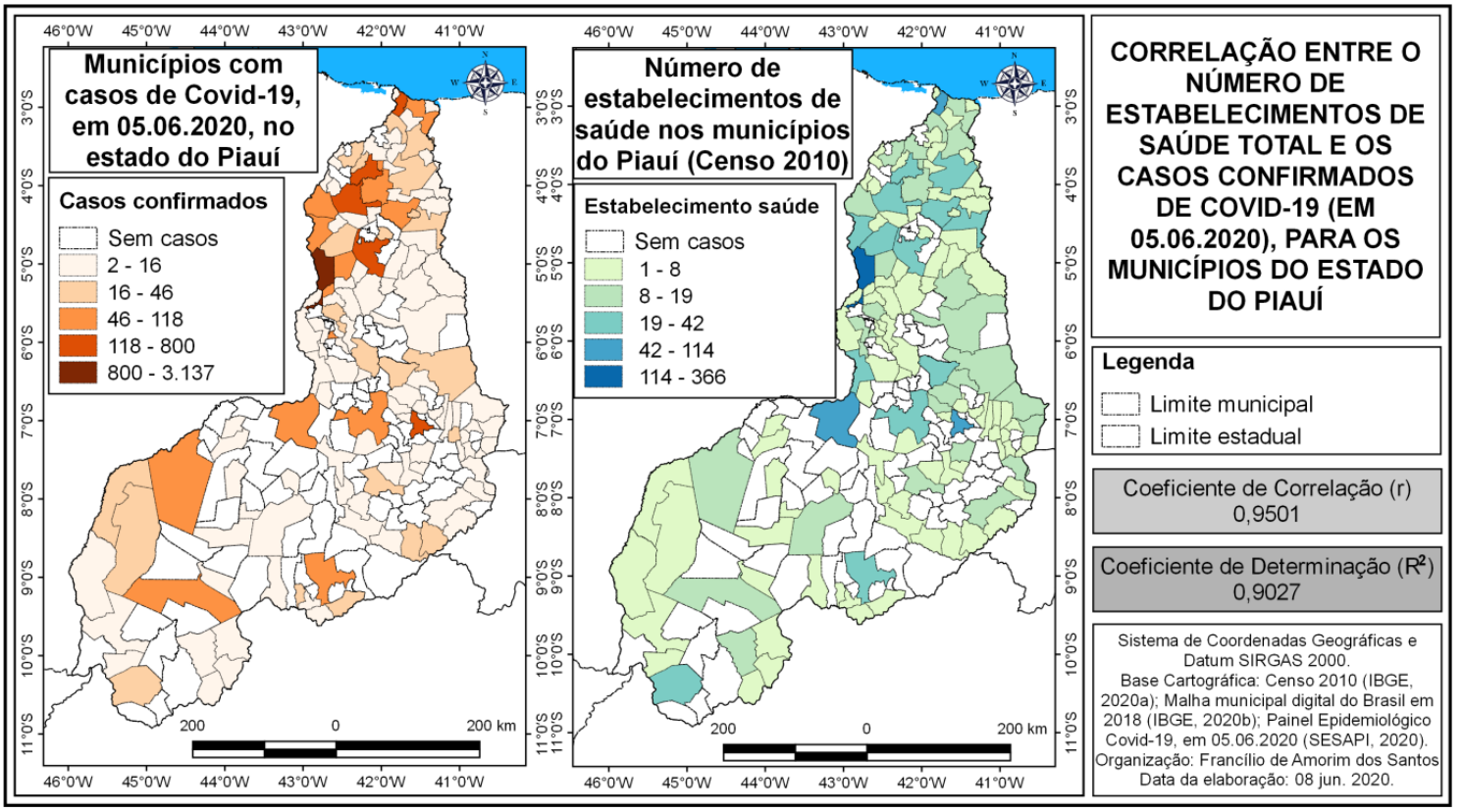

Fonte: IBGE (2020a; 2020b); SESAPI (2020). Organizado por Santos (2020).

\section{Análise estatística multivariada/análise de agrupamentos}

Quando realizado o agrupamento dos municípios por similaridade em relação à população do sexo feminino, observou-se um predomínio do cluster 1 (Figura 9) pois, dentre os 167 municípios considerados no estudo, 154 situam-se no cluster 1, com São Miguel da Baixa Grande apresentando o menor contingente de pessoas do sexo feminino, 1.060 pessoas, enquanto São Raimundo Nonato apresenta o maior contingente, 16.430 pessoas do sexo feminino. Por sua vez, os cluster 2 (18.563 (José de Freitas) a 22.284 pessoas do sexo feminino (Barras)), cluster 3 (23.396 (Campo Maior) a 38.353 pessoas do sexo feminino (Picos)), cluster 4 (Parnaíba, com 75.978 mulheres) e cluster 5 (Teresina, com 433.618 pessoas do sexo feminino), respectivamente, agrupam 7, 4, 1 e 1 municípios. Reitera-se que no cluster 1 agrupamse os municípios de pequeno porte, enquanto no cluster 5 ficou apenas o município de Teresina, que apresenta o maior contingente populacional e, consequentemente, quando observados os casos de Covid19 justifica-se a maior de casos nesse último município.

A similaridade dos municípios piauienses no que se refere à população do sexo masculino apontou a preponderância do cluster 1 (Figura 10), situando-se nesse grupo 162 municípios, sendo São Miguel da Baixa Grande o que apresentou a menor quantidade de pessoas do sexo masculino (1.050 pessoas), enquanto Barras (22.566 homens) constituiu o outro extremo. Por outro lado no cluster 2 ficaram agrupados os municípios de Floriano (27.309 pessoas do sexo masculino) e Piripiri (30.138 homens), no cluster 3 ficou apenas o município de Parnaíba (69.727 pessoas do sexo masculino), no cluster 4 o município de Picos (35.061 pessoas do sexo masculino) e no cluster 5 apenas a capital Teresina (380.612 homens). Reitera-se que os clusters agruparam-se dos municípios de menor porte para o de maior porte. 
Figura 9 - Similaridade da população do sexo feminino nos municípios do estado do Piauí.

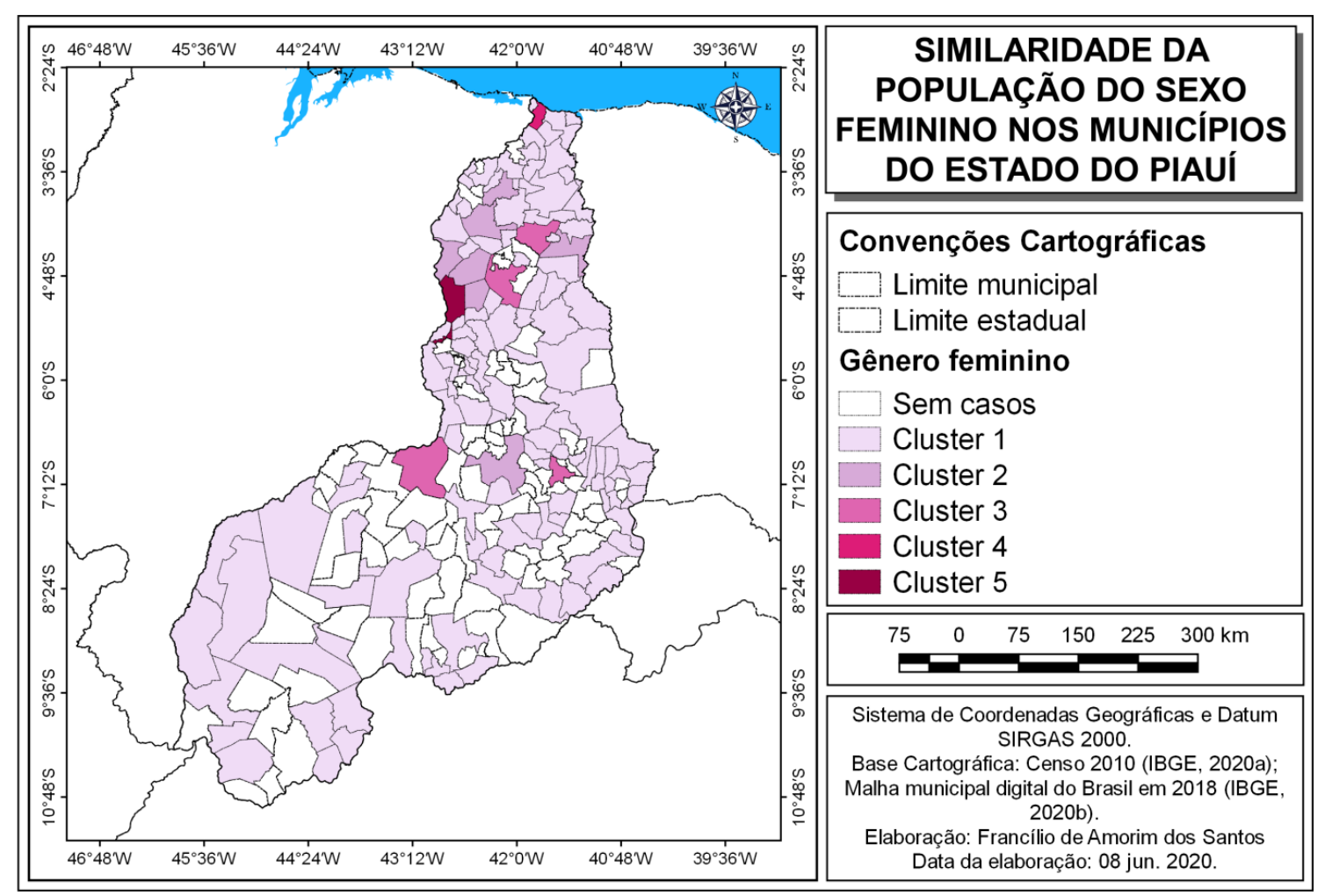

Fonte: IBGE (2020a; 2020b). Elaborado por Santos (2020).

Figura 10 - Similaridade da população do sexo masculino nos municípios do estado do Piauí.

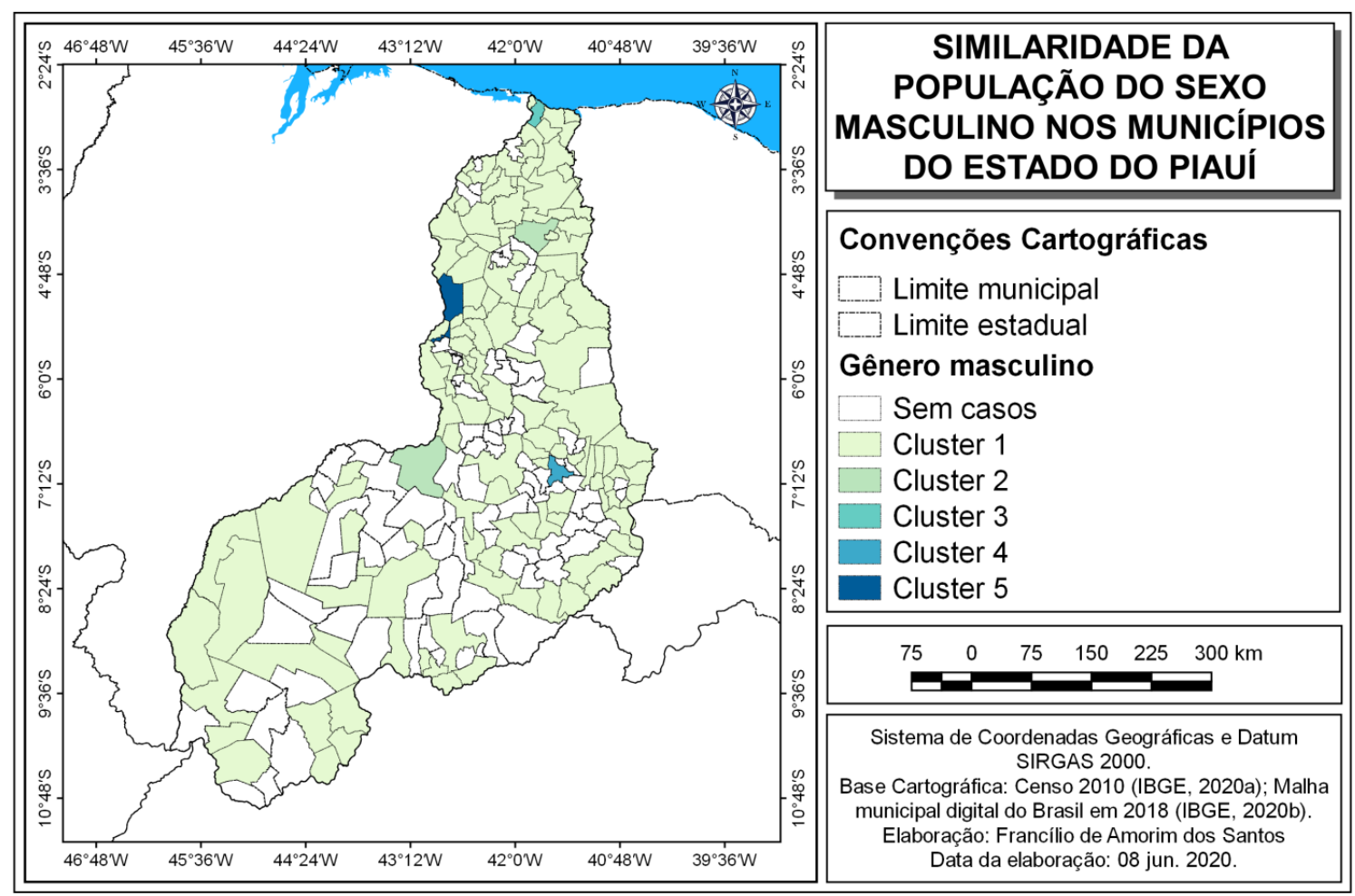

Fonte: IBGE (2020a; 2020b). Elaborado por Santos (2020). 
No que concerne à similaridade da população com 65 anos de idade ou mais, no cluster 1 foram agrupados 154 municípios (Figura 11), onde o município de Pedro Laurentino apresentou a menor quantidade de pessoas com $\geq 65$ anos (153 pessoas) e o município de Miguel Alves a maior quantidade (2.357 pessoas). Por sua vez, no cluster 2 encontram-se 7 municípios, partindo de Esperantina com 2.938 idosos a União, que possui 3.518. Por seu turno, o cluster 3 apresenta 4 municípios, tendo o município de Campo Maior o menor contingente (4.110 pessoas com $\geq 65$ anos) e o município de Piripiri (5.458 pessoas com $\geq 65$ anos). Os clusters 4 e 5 apresentaram apenas um município em cada grupo, respectivamente, Parnaíba (11.072 pessoas com $\geq 65$ anos) e Teresina (46.113 pessoas com $\geq 65$ anos), fato que justifica serem esses dois municípios aqueles com maior número de casos confirmados de infecção por SARS-CoV-2.

Figura 11 - Similaridade da população com 65 anos de idade ou mais nos municípios do estado do Piauí.

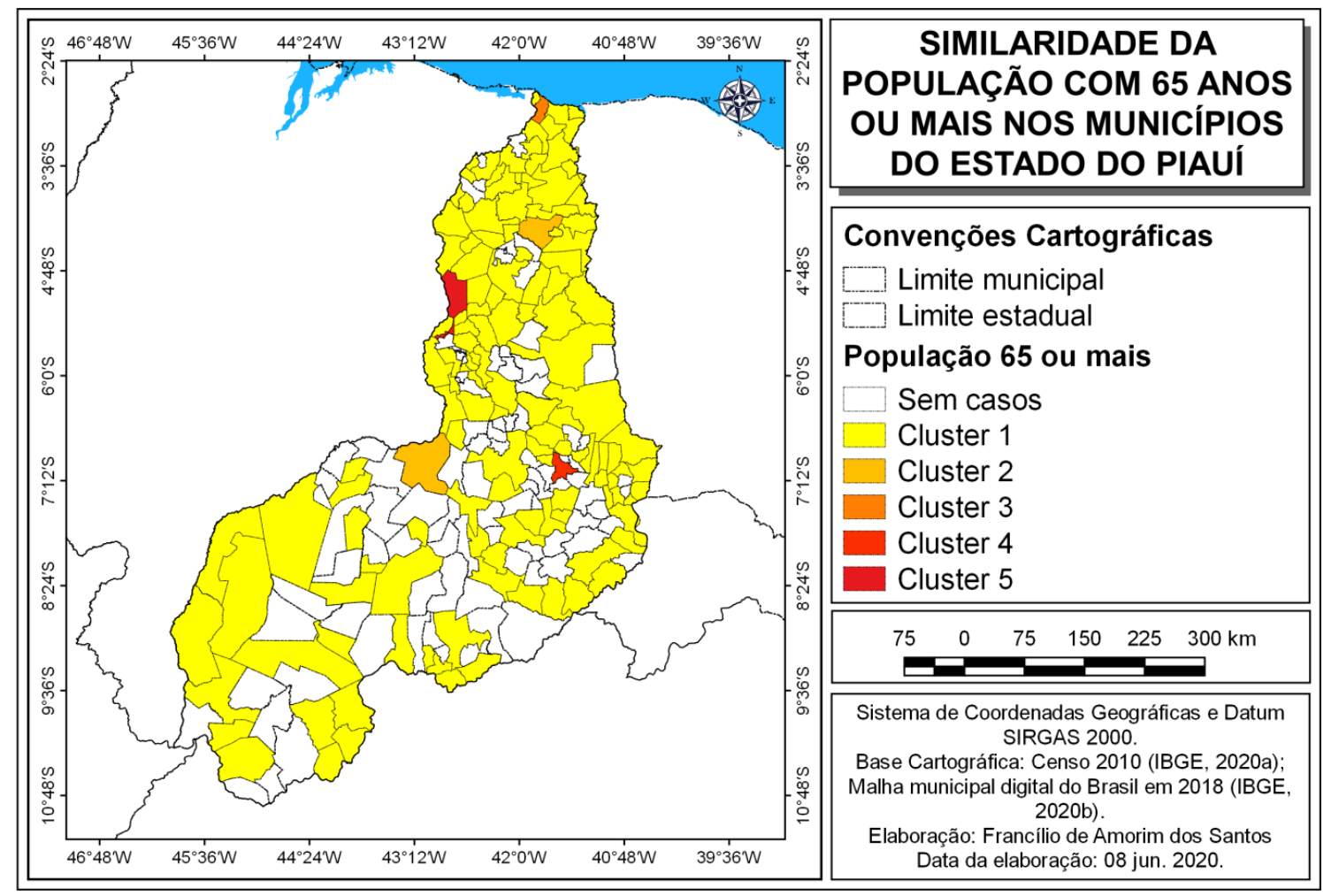

Fonte: IBGE (2020a; 2020b). Elaborado por Santos (2020).

O agrupamento por similaridade em relação ao número de estabelecimentos de saúde total apontou que no cluster 1 foram agrupados 163 municípios (Figura 12), sendo que os municípios de Barreiras do Piauí, Belém do Piauí, Boa Hora, Cajazeiras do Piauí, Coivaras, Curral Novo do Piauí, Lagoa do Sítio, Madeiro, Pau D'Arco do Piauí, Pavussu e Pedro Laurentino apresentam apenas 1 estabelecimento e o município de Valença do Piauí, aquele que apresentou a maior quantidade (42 estabelecimentos), conforme indicam os dados do (IBGE, 2020a). Os demais clusters ficaram cada um com apenas um município incluído, a saber: cluster 2, município de Floriano com 66 estabelecimentos; cluster 3 , município de Parnaíba com 85 estabelecimentos; cluster 4, município de Picos com 114 estabelecimentos de saúde; cluster 5 , município de Teresina que conta com 366 estabelecimentos. Deve-se atentar para o fato de que esses últimos clusters apresentam o maior número de estabelecimentos de saúde, contudo esses municípios funcionam como polo atrativo em relação às internações e tratamento dos casos de Covid-19 e, desse modo, deve ser observada sempre suas capacidades de saturação, caso contrário o sistema de saúde entrará em colapso. 
Figura 12 - Similaridade do número de estabelecimentos de saúde total nos municípios do estado do Piauí.

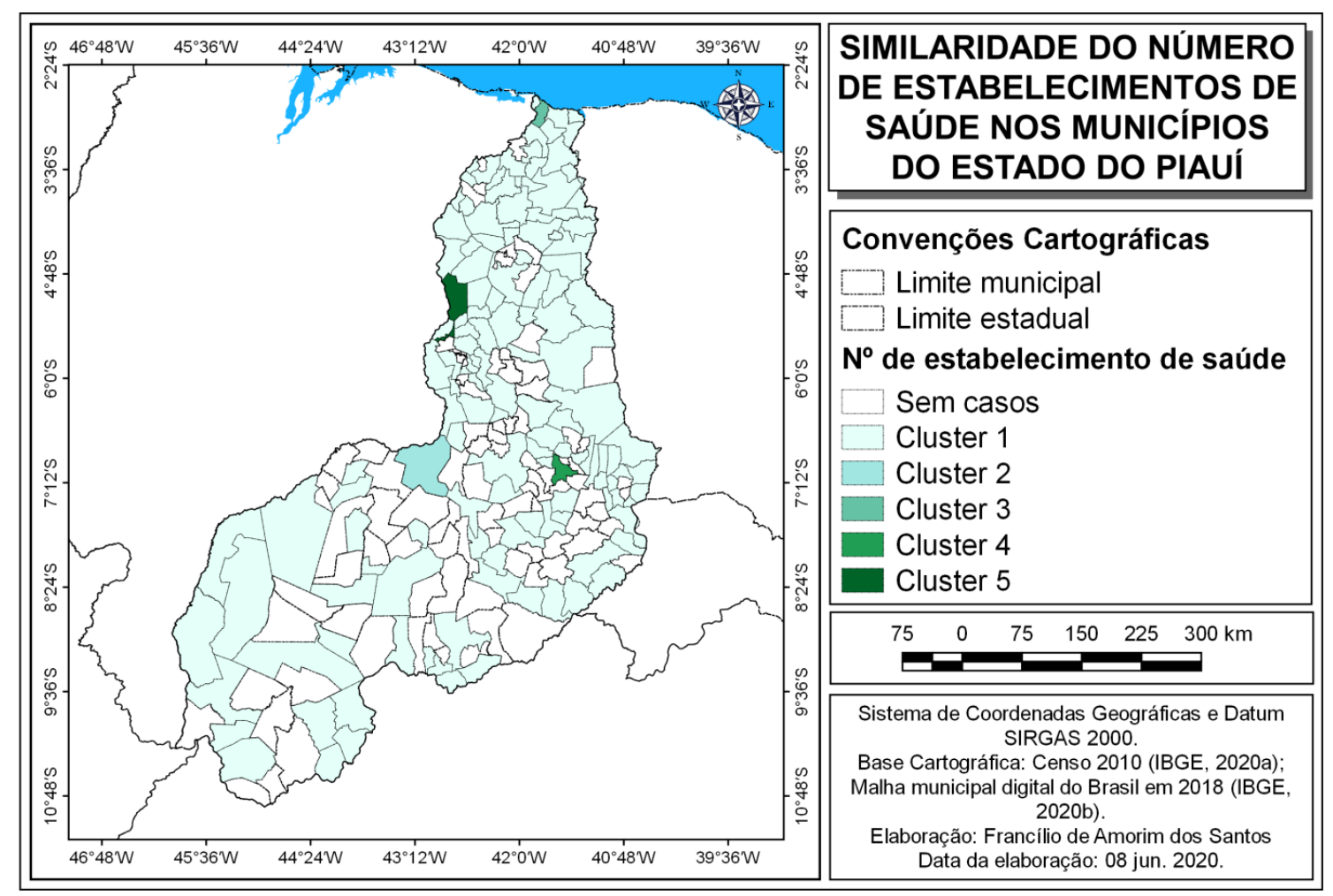

Fonte: IBGE (2020a; 2020b). Elaborado por Santos (2020).

A similaridade dos municípios com casos confirmados de Covid-19 apontou que no cluster 1 encontrou-se 161 municípios e no cluster 2 situaram-se 3 municípios (Figura 13), enquanto no cluster 3 , cluster 4 e cluster 5 foi registrado 1 município em cada. Deve-se destacar que no cluster 1 situam-se, principalmente, os municípios com maior contingente populacional do sexo feminino, maior proporção de pessoa com $\geq 65$ anos ou mais de idade e menor quantidade de estabelecimentos de saúde total. Já nos cluster 4 e 5 destacaram-se, respectivamente, os municípios Parnaíba e Teresina como aqueles de maior contingente de pessoas com casos confirmados, são os dois mais populosos municípios do estado e possuem a mais numerosa infraestrutura hospitalar para atendimento aos casos de infecção por Covid-19.

Em relação ao número de óbitos, a similaridade entre os municípios piauienses demonstrou que o cluster 1 apresentou 160 municípios incluídos (Figura 14). Nesse grupo estão os municípios de menor porte, com contingente populacional abaixo de 50 mil habitantes. No cluster 2 ficou apenas o município de Água Branca, enquanto no cluster 3 agruparam-se os municípios de Altos, Piripiri, Campo Maior e Picos, considerados municípios de contingente populacional acima de 50 mil habitantes, executandose o município de Altos. Os clusters 4 e 5 englobaram, respectivamente, os municípios de Parnaíba e Teresina, aqueles com maior contingente populacional e maior quantidade de casos confirmados de infecção por Covid-19. 
Figura 13 - Similaridade dos casos confirmados de covid-19 (em 05.06.2020) nos municípios do estado do Piauí.

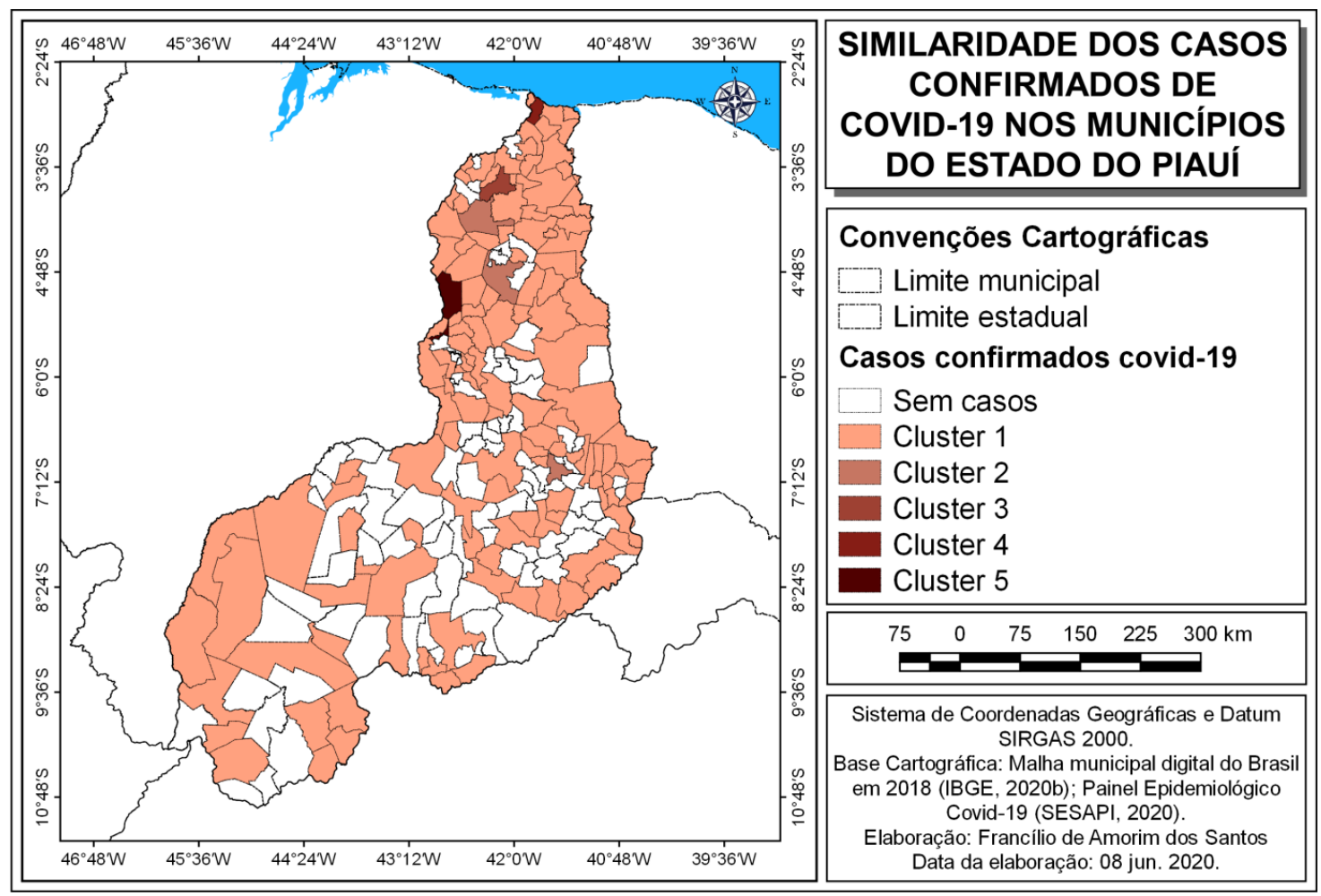

Fonte: IBGE (2020a; 2020b); SESAPI (2020). Elaborado por Santos (2020).

Figura 14 - Similaridade do número de óbitos (em 05.06.2020) nos municípios do estado do Piauí.

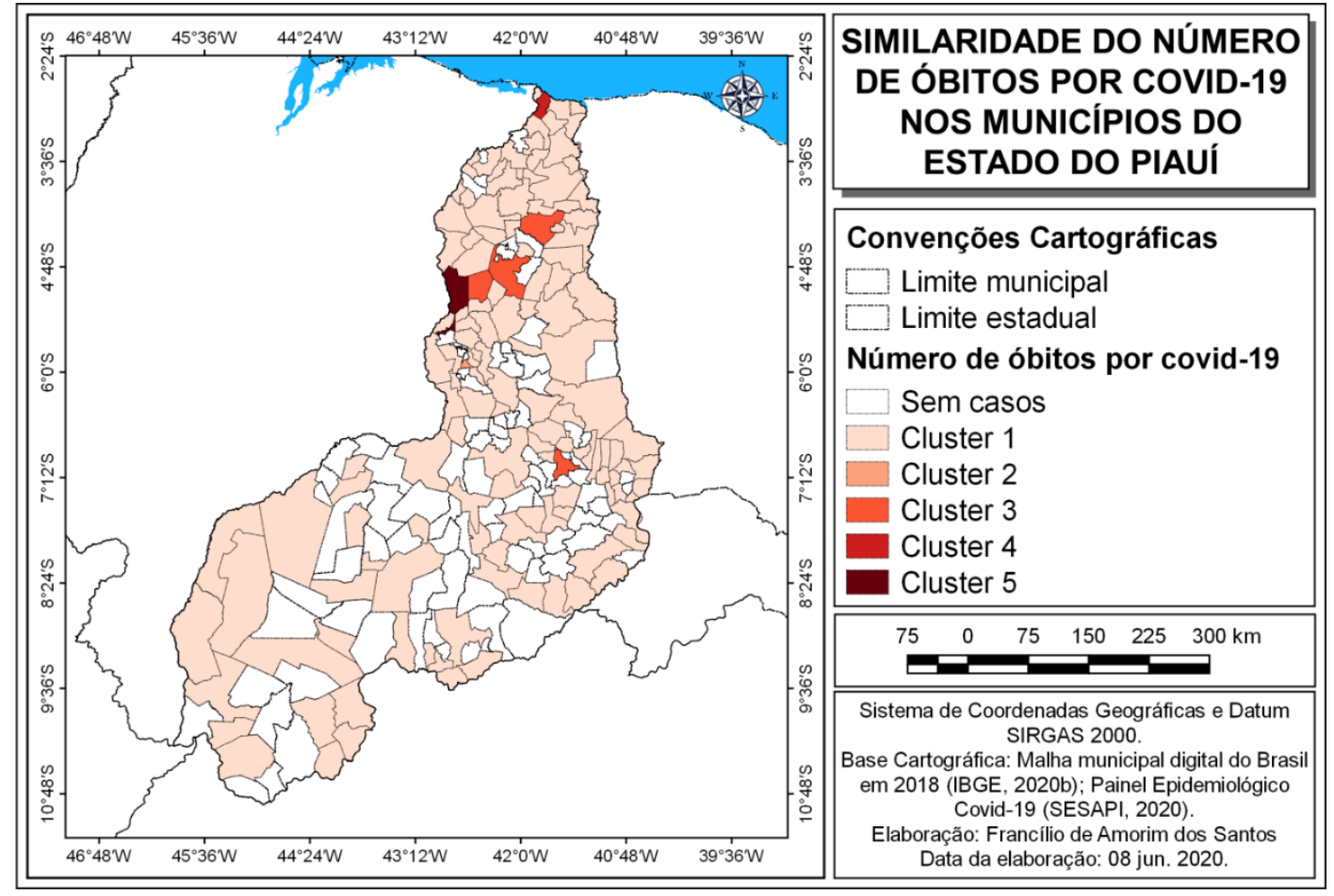

Fonte: IBGE (2020a; 2020b); SESAPI (2020). Elaborado por Santos, 2020. 


\section{CONSIDERAÇÕES FINAIS}

O emprego da Cartografia e de técnicas estatísticas para agrupar informações acerca do Covid-19 foi relevante. Pois o estudo possibilitou a espacialização de quatro variáveis (gênero masculino e feminino, população residente com idade $\geq 65$ anos, número de estabelecimentos de saúde total) do IBGE que estão fortes e positivamente ligadas ao número de casos de Covid-19 confirmados e número de óbitos, de acordo com os gráficos da SESAPI. Já a espacialização dos dados referentes ao contingente populacional de pessoas do sexo masculino e feminino, quantidade de pessoas com 65 anos ou mais e o número de estabelecimentos de saúde total permitiu a realização de correlação com os casos confirmados e número de óbitos e, ainda, o agrupamento dos municípios por similaridade.

As 4 variáveis independentes (pessoas do sexo masculino e feminino, quantidade de pessoas com 65 anos ou mais e o número de estabelecimentos de saúde total) mostram-se fortemente e positivamente relacionadas ao quantitativo de casos confirmados de infecção por Covid-19, bem como o modelo utilizado, que também se mostrou adequado. Desse modo, reitera-se a necessidade de atenção frente a influência dessas variáveis sobre a infecção, particularmente para a população com 65 anos ou mais de idade, tida como uma das mais vulneráveis de acordo com a OMS.

Quando analisados os municípios por sua similaridade pode-se observar que nos clusters 1 agrupam-se aqueles municípios considerados de pequeno porte, de menor contingente populacional e menor quantitativo de estabelecimentos de saúde. Por outro lado no cluster 5 ficou apenas o município de Teresina, capital do estado, que apresenta o maior contingente populacional e, dessa forma, também maior quantidade de pessoas com 65 anos ou mais de idade, além do maior número de estabelecimentos de saúde total. Destaca-se, ainda, o município de Parnaíba que ficou no cluster 4 em relação aos casos confirmados de infecção por SARS-CoV-2, tendo no dia 05 de junho 800 casos.

O estudo, em síntese, apontou os municípios com maior quantitativo de casos confirmados de infecção e óbitos por Covid-19, cuja variação está fortemente relacionada às variáveis independentes consideradas no estudo. Desse modo, ressalta-se a relevância dessa pesquisa como ponto de partida para direcionamento dos investimentos emergenciais e, futuramente, o desenvolvimento de políticas públicas, particularmente na área da saúde, para mitigar os efeitos oriundos da pandemia. Deve-se, ainda, pensar em outras perspectivas metodológicas, para além da que foi empregada, como possibilidade para alcançar resultados mais robustos e que deem suporte ao planejamento municipal.

\section{REFERÊNCIAS}

ALMAGRO, M.; ORANE-HUTCHINSON, A. The determinants of the diferential exposure to COVID19 in New York City and their evolution over time. Publicado em 29 abr. 2020. Disponível em: <https://m-almagro.github.io/Covid and Within City Inequality.pdf>. Acesso em: 04 jun. 2020.

BAPTISTA, J.G. Geografia Física do Piauí. 2. ed. Teresina: COMEPI, 1981.

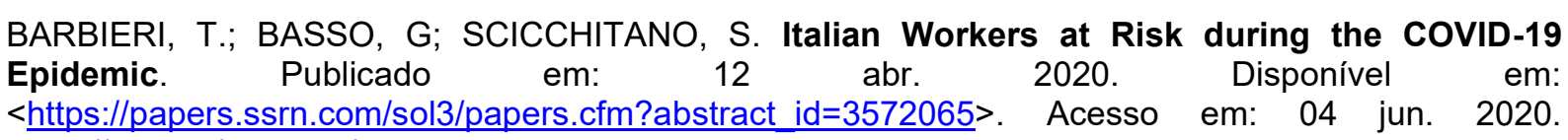
https://doi.org/10.2139/ssrn.3572065

BELFORTE, L.C.M.; REIS, R.S.P.; SILVA, G.P.; CAVALCANTE, M.M.A. Leitura geográfica no contexto da covid-19 em Rondônia ao norte do Brasil. Revista Tamoios, São Gonçalo, n.1, p.145-153, maio 2020. https://doi.org/10.12957/tamoios.2020.50379

GERALDI, L.H.O.; SILVA, B.C.N. Quantificação em Geografia. São Paulo: DIFEL, 1981.

IN LOCO. Mapa brasileiro da covid-19. Disponível em: $<$ https://mapabrasileirodacovid.inloco.com.br/pt/? hstc=227211714.fb21c85cbf78920876ba80f9f37f0 6a0.1591836243834.1591836243834.1591836243834.1\& $\quad$ hssc $=227211714.1 .1591836243835 \& \quad h$ $\underline{\mathrm{sfp}}=433084368$ \&hsCtaTracking $=68943485-8 \mathrm{e} 65-4 d 6 f-8 \mathrm{ac0}-\mathrm{af7c3ce} 710 \mathrm{a} 2 \%$ 7C45448575-c1a6-42c886d9-c68a42fa3fcc>. Acesso em: 09 jun. 2020.

INSTITUTO BRASILEIRO DE GEOGRAFIA E ESTATÍSTICA. Censo 2010. Disponível em: $<$ https://censo2010.ibge.gov.br/resultados.html>. Acesso em: 04 jun. 2020a. 
Malha municipal digital do Brasil: situação em 2018. Rio de Janeiro: IBGE, 2018. Disponível em: <ftp://geoftp.ibge.gov.br/malhas digitais/>. Acesso em: 18 abr. 2020b. 2020c. Piauí. Disponível em: <https://cidades.ibge.gov.br/brasil/pi/historico>. Acesso em: 04 jun.

LIMA, I.M.M.F.; ABREU, I.G.; LIMA, M.G. Semi-árido Piauiense: delimitação e regionalização. Carta CEPRO, Teresina, v.18, p.162-183, 2000.

MINGOTI, S.A. Análise de dados através de métodos de estatística multivariada: uma abordagem aplicada. Belo Horizonte: Editora UFMG, 2005. 297p.

ORGANIZAÇÃO MUNDIAL DE SAÚDE. Coronavírus: novos dados sobre grupos de risco. Disponível em: <https://saude.abril.com.br/medicina/coronavirus-novos-dados-sobre-grupos-de-risco/>. Acesso em: 04 jun. 2020.

Portal Action. Coeficiente de determinação. Disponível em: <http://www.portalaction.com.br/analisede-regressao/16-coeficiente-de-determinacao>. Acesso em: 04 jun. 2020.

ROGERSON, P.A. Métodos estatísticos para geografia: um guia para o estudante. Tradução técnica: Paulo Fernando Braga Carvalho, José Irineu Rangel Rigotti. 3. ed. Porto Alegre: Bookman, 2012. 348p.

SECRETARIA DE ESTADO DA SAÚDE DO PIAUÍ. Painel Epidemiológico Covid-19: Piauí. Disponível em: <https://datastudio.google.com/u/0/reporting/a6dc07e9-4161-4b5a-9f2a6f9be486e8f9/page/2itOB >. Acesso em: 09 jun. 2020.

SHEPHERD, M. Geografia pode ser a chave para lutar contra o surto de COVID-19. Publicado em: 12 mar. 2020. Disponível em: <https://mundogeo.com/2020/03/12/geografia-pode-ser-a-chave-paralutar-contra-o-surto-de-covid-19/>. Acesso em: 18 abr. 2020.

SILVA, A.J.P.; LOPES, R.C.; VASCONCELOS, A.M.; BAHIA, R.B.C. Bacias Sedimentares Paleozóicas e Meso-Cenozóicas Interiores. In: BIZZI, L.A.; SCHOBBENHAUS, C.; VIDOTTI, R.M.; GONÇALVES, J.H. (eds.). Geologia, Tectônica e Recursos Minerais do Brasil. CPRM, Brasília, 2003. p.55-85.

SPOSITO, M.E.B.; GUIMARÃES, R.B. Por que a circulação de pessoas tem peso na difusão da pandemia. Publicado em: 26 mar. 2020. Disponível em: $<$ https://www2.unesp.br/portal\#!/noticia/35626/por-que-a-circulacao-de-pessoas-tem-peso-na-difusaoda-pandemia>. Acesso em: 18 abr. 2020. 